\title{
Does Climate Change Mitigation Activity Affect Crude Oil Prices? Evidence from Dynamic Panel Model
}

\author{
Jude C. Dike \\ Economics Division, University of Stirling, Cottrell Building, Stirling FK9 4LA, UK \\ Correspondence should be addressed to Jude C. Dike; j.c.dike@stir.ac.uk
}

Received 3 August 2014; Revised 31 October 2014; Accepted 23 November 2014; Published 11 December 2014

Academic Editor: Jin-Li Hu

Copyright (C) 2014 Jude C. Dike. This is an open access article distributed under the Creative Commons Attribution License, which permits unrestricted use, distribution, and reproduction in any medium, provided the original work is properly cited.

\begin{abstract}
This paper empirically investigates how climate change mitigation affects crude oil prices while using carbon intensity as the indicator for climate change mitigation. The relationship between crude oil prices and carbon intensity is estimated using an Arellano and Bond GMM dynamic panel model. This study undertakes a regional-level analysis because of the geographical similarities among the countries in a region. Regions considered for the study are Africa, Asia and Oceania, Central and South America, the EU, the Middle East, and North America. Results show that there is a positive relationship between crude oil prices and carbon intensity, and a $1 \%$ change in carbon intensity is expected to cause about $1.6 \%$ change in crude oil prices in the short run and $8.4 \%$ change in crude oil prices in the long run while the speed of adjustment is $19 \%$.
\end{abstract}

\section{Introduction}

Many factors influence the prices of crude oil globally and paramount among these factors are supply and demand activities [1-3], market speculations [4,5], taxes [6], war, and political instability [7]. These factors have been documented empirically to have significant effects on crude oil prices $[8,9]$. The Organisation of Petroleum Exporting Countries (OPEC) as the major global crude oil producers and suppliers have been concerned about these factors especially the ones which from their point of view have adverse effects on the prices of crude oil [10].

Recently, the focus of the global energy industry has shifted to the carbon contents of fossil based energy sources especially with the global spotlight on carbon emissions reduction [11]. This paradigm shift and the extension of Kyoto Protocol's commitment period to 2020 (i.e., the second commitment period 2013-2020) have thrown up a major economic challenge for countries that are dependent on crude oil export revenues especially OPEC [10]. One of the issues related to this new economic threat perceived by OPEC is the pricing of crude oil under the new climate regime(s). To shed more light on this issue, this paper attempts to determine the relationship between crude oil prices and climate change mitigation activity.

To carry out the required investigation in this paper, climate change mitigation activity is represented by a proxy indicator. This study opts for a proxy indicator in order to capture the climate change mitigation activities that have the tendency to impact on crude oil consumption and/or production. The proxy indicator for climate change mitigation chosen for this study is carbon intensity which shows the level of carbon utilisation in the economy [12-14]. Carbon intensity is preferred as a proxy indicator because it is derived from all sectors of the economy and captures all carbon-related climate mitigation effects whether in the short term or long term and there are data on carbon intensity levels that cover the period under consideration [15-17]. The carbon intensity data are derived at consumption level instead of production level because of the different regions considered by the model. The measurement of carbon intensity at production levels may lead to double counting as some intermediate products exported to other countries will be taken into account in the exporting and importing countries. However, the measurement of carbon intensity at consumption level allows the transfer of emission from country or region of production 
to the country or region of consumption where intercountry or interregional trades exist. Other indicators considered initially are greenhouse gases emissions and per capita emissions [18] but carbon intensity is more compatible to the model used for this study. While greenhouse gases emissions consider all the gases emitted, carbon intensity considers only $\mathrm{CO}_{2}$ related emissions. On the other hand, per capita emissions indicator considers total emissions per person while carbon intensity considers total emissions per economic output. The a priori and theoretical assumption is that crude oil consumption is affected when carbon reduction strategies (such as carbon taxes) are introduced to reduce carbon dioxide $\left(\mathrm{CO}_{2}\right)$ emissions $[19,20]$. This paper's model also estimates how fast crude oil prices change when carbon intensity changes.

To estimate the relationship between crude oil prices and carbon intensity including short run effects, long run effects, and the speed of adjustment, this paper explores the ArellanoBond $(A B)$ dynamic panel model [21]. The results of this study indicate that there is a positive relationship between crude oil prices and carbon intensity suggesting that there is a relationship between crude oil prices and climate change mitigation activity in the regions under consideration in the short run and long run, respectively.

This paper is presented in five sections. The following section looks at the structure of the crude oil market, related studies in the literature, and the sources and nature of the data used for the study. Section 3 explores the methodology of the study and Section 4 addresses the presentation and discussion of the results while Section 5 covers the conclusion.

\section{Literature Review and Background to the Study}

2.1. The Structure of the Crude Oil Market. The global crude oil market has been described theoretically as an oligopolistic market [22]. It is said that the long term marginal cost of oil is a small fraction of oil price [23]; therefore, the prices are driven by the restriction of excess supply by the market supply leader. Such scenario describes the OPEC monopolistic theory, where higher cost producers sell all they can produce and the low cost producers satisfy the market supply shortage or excess demand at current prices and could as well restrict production [22]. There is econometric evidence that confirms this position about Saudi Arabia, which plays the role of a "swing" producer [22]. Other studies also support the oligopolistic nature of the oil market and the market dominance by Saudi Arabia and OPEC [24-26].

On the other hand, the demand for crude oil is driven by the choices of individual households/firms as well as other private interest groups such as refineries because of the economic and national security importance of oil [22]. The dependence of the economy and national security on oil makes it inevitable for oil importing countries to influence oil demand (just like oil exporting countries influence the supply). Therefore, the oil market is also influenced by the oil importing countries. These influences could be in the form of investing public funds in the development of alternative energy sources (in order to create substitutes), explorations based on advanced technology, fiscal instruments, environmental regulations, political interventions, strategic oil reserves, and so forth $[22,27,28]$.

However, it has been established in the literature that the crude oil market is also competitive especially on determination of prices, where the forces of supply and demand determine the spot market prices [22, 29, 30]. According to Hamilton [30] there are three separate conditions that hold in equilibrium in the dynamic crude oil market and these conditions are storage/inventory, futures markets, and scarcity rent factors.

In the competitive oil market, spot prices are the market prices against the official prices (OPEC or major oil companies determined) that were more influential in the 1970 s and early 1980s because the petroleum industry has become increasingly dependent on the spot prices which also determine the term and futures prices [27].

The major factors that affect crude oil demand and supply are therefore expected to affect crude oil prices as well. Inasmuch as the global oil market is seen as competitive, there are situations where market failure occurs which may lead to imperfect competition. When a market failure occurs, the price of crude oil would be affected.

This study assumes that while the market is competitive it is dynamic and not fully transparent which brings about market failure. Theoretically, the introductions of climate change mitigation policies are expected to have major impacts on the oil market. Energy efficiency methods and subsidy on renewable energy sources are market driven climate change mitigation policies while carbon taxes are public/government driven policies that also distort the market. When energy efficiency policies are introduced, the demand falls over time and such demand shocks are eventually transmitted to the market. When renewable energy sources are subsidised, the substitution effect comes into play and demand for oil also falls over time. However, when carbon taxes are introduced, it disrupts the competitive markets situation or equilibrium by driving up crude oil prices which enhances the economic activities to discover adequate noncarbon/less-carbon substitutes for oil over time. Therefore, it is assumed that even when oil demand tends to be price inelastic or have low price elasticity [30], the combination of the energy efficiency driven demand shocks, renewable energy subsidy driven substitution effects, and carbon tax driven market distortion may affect oil prices, if not in the short term then in the long term.

2.2. Related Studies in the Literature. Climate change mitigation activity entails any activity or policy related to the reduction of greenhouse gases emissions [19]. Among the greenhouse gases, $\mathrm{CO}_{2}$ accounts for over fifty percent $(50 \%)$ of the sources of global warming [31]. It is also established by the UNFCCC [31] that fossil fuels (coal, oil, and gas) are the major sources of $\mathrm{CO}_{2}$ emissions and are responsible for about fifty-six percent (56\%) of the total global $\mathrm{CO}_{2}$ emission. So, it is assumed that major activities that will reduce $\mathrm{CO}_{2}$ emissions would take fossil fuel consumption into consideration.

The level of carbon intensity is defined as the standard or basis for measuring the utilisation of carbon emitting 


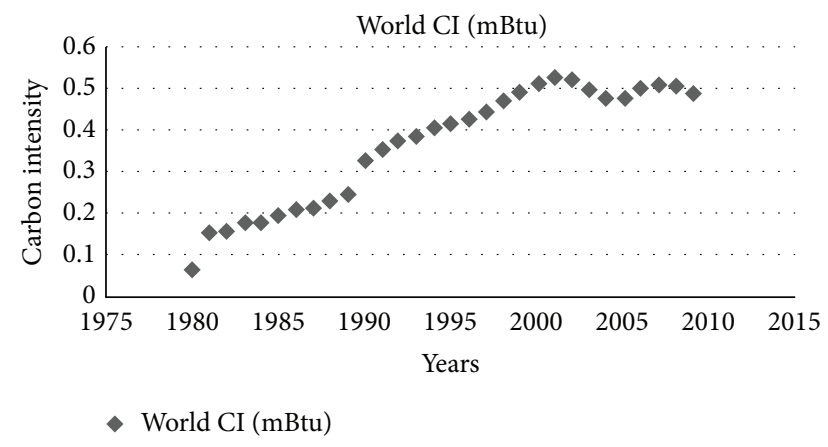

FIgURE 1: Annual carbon intensity levels.

resources in the economy [32]. In this paper, it is assumed in line with EIA [32] that carbon intensity accounts for the economy wide carbon utilisation level which can also show the carbon reduction level.

Carbon intensity levels are not as flexible as crude oil prices. The volatility of carbon intensity levels is shown in Figure 1. Figures 1 and 2 show the annual levels of carbon intensity and crude oil prices for a period of thirty-two (32) years (1980-2011). The carbon intensity levels follow a trend while crude oil prices are more volatile over the same period.

Carbon intensity is also described as the carbon dioxide emissions per unit of total primary energy supply in the economy [12, 19,32] or according to the EIA [32] carbon intensity level is an energy consumption weighted average of its emissions coefficients (emissions coefficient is a unique value for scaling emissions to activity data in terms of a standard rate of emissions per unit of activity (e.g., weight of carbon emitted per Btu of fossil fuel consumed)).

Kaya [12] identifies carbon intensity, energy intensity, gross domestic product per capita, and population as indicators for the level of energy related carbon emissions. Energy Modelling Forum [33] indicates that climate change mitigation activity or policy such as carbon tax would likely reduce (affect) carbon intensity of an economy's total energy consumption. OECD [34] also states that "ongoing efficiency gains" (mitigation activity) are expected to contribute to the decline in carbon intensity levels. This position is supported by the IPCC [19] which further states that the change in carbon intensity as a result of $\mathrm{CO}_{2}$ reduction may affect oil prices and oil exporters' economy. According to IPCC [19] and several studies in the literature, the mitigation of greenhouse gases emissions is expected to affect oil price. Among these studies are Ghanem et al. [35]; Pershing, [36]; Barnett et al. [20]; and Awerbuch and Sauter [37].

Barnett et al. [20] discuss the different global energy economy models which suggest that climate policies and measures supported by the Kyoto Protocol and subsequent negotiations would see a reduction in the consumption of crude oil products in developed countries thereby leading to a decline in global oil demand. According to Henman [38], these energy economy models have been influential in the political economy of climate change. In the short run, when climate change mitigation activity is introduced in developed countries or Annex 1 countries under the Kyoto Protocol, which account

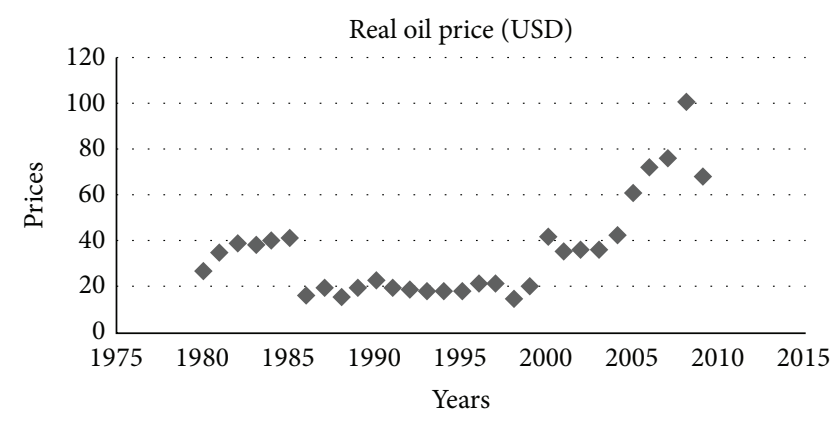

- Real oil price (USD)

Figure 2: Annual crude oil prices.

for $60 \%$ of world oil consumption [20], oil prices would rise, thereby leading to a fall in oil demand. As a result of this reduction in oil demand, prices may decline in the long run. The effects of Annex 1 countries climate mitigation policies and measures on oil prices might occur through carbon taxes applied according to the carbon content of oil [20,39].

In the different models used to estimate the impact of climate mitigation activity on oil exporting countries, G-cubed model, McKibbin and Wilcoxen [40], OPEC World Energy model (OWEM), Ghanem et al. [35], MS-MRT model, Bernstein et al. [41], CLIMOX model, Bartsch and Muller [42], GREEN model, Pershing [36], and GTEM model, Polidano et al. [43], it was found that climate change mitigation affects energy prices (including crude oil prices). Awerbuch and Sauter [37] in their model found that a $10 \%$ increase in renewable energy sources especially in the electricity sector would reduce $\mathrm{CO}_{2}$ by $3 \%$ and global oil price reduction would be in the range of $3 \%-10 \%$. However, this study is different from the above models as it is based on a dynamic panel model which shows the short and long terms impacts and focuses on climate change mitigation activities in six regions, Africa, Asia and Oceania, Central and South America, the EU, the Middle East, and North America. This study undertakes a regionallevel analysis because of the geographical similarities among the countries in a region.

Based on the existing studies, this paper assumes that causality runs from carbon intensity to crude oil prices. Although sudden changes in crude oil prices may affect some climate change mitigation policies and measures such as technological innovation in the long run, this study assumes that this effect may not be significant because of the growing consensus on the impacts of climate change and there are other factors that drive technological innovations other than crude oil prices $[44,45]$. However, in this study, there is a provision to take care of endogeneity by using the $\mathrm{AB}$ dynamic panel model, which uses lagged explanatory variables as instruments.

Apart from carbon intensity, other climate change mitigation related factors and other factors affect crude oil prices and they are covered by the stochastic term in the model. This study also makes provision for controls and some other deficiencies in the data by introducing some categorical variables to account for the outliers observed as possible structural 
breaks in the crude oil prices' data. Some other factors are not included because of lack of or insufficient data.

2.3. Data. The data used for the study covers the period from 1980 to 2011 . The carbon intensity data are from the US Energy Information Administration (EIA) online database. The carbon intensity data for all the regions are derived using market exchange rates (metric tons of carbon dioxide per thousand year 2005 US Dollars). This feature makes carbon intensity a good indicator because crude oil is priced in US Dollars as well. For the different regions, certain countries are considered due to the availability of data on carbon intensity for the period under consideration. The study focuses on regions because the country level data for some countries of interest are so small that they may lead to poor statistical results. The crude oil price data are collated from the International Energy Agency (IEA) database and OPEC Annual Statistical Bulletin (OPEC Statistical Bulletins (1980-2011)). The OPEC prices are based on a weighted average index of currency exchange rates in the modified Geneva I Agreement. The crude oil prices data are diversified as follows; the prices from 1980 to 1981 are based on the posted prices of the Arab Light. The prices from 1982 to 2005 are based on the OPEC Reference Basket and from 2005 to 2009 the prices are based on OPEC's new Basket methodology. The US WTI prices are used for the North America region, UK Brent prices for the EU, Nigerian Light crude prices for Africa region, Saudi Arabian Light crude prices for Middle East region, Indonesia Minas crude prices for Asia/Oceania region, and Venezuela Light crude prices for South/Central America region. These prices are reported in US Dollars and are adjusted for inflation to 2011 Consumer Price Index (CPI). The data are estimated in log forms.

\section{Methodology and Modelling Framework}

This study utilizes the AB dynamic panel model because the regressor(s) may be correlated with the error term $E_{i t}$. The $\mathrm{AB}$ dynamic panel model is also considered because of the time-invariant regional characteristics (fixed effects) such as geographical and demographic factors which may be correlated with the explanatory variables. The AB dynamic panel model also takes care of the problems related to the presence of the lagged dependent variable $P_{i t-1}$ as a regressor.

The standard model for this dynamic panel study is specified below using the Arellano-Bond GMM approach (Arellano and Bond, op. cit):

$$
P_{i t}=\gamma P_{i t-1}+\beta C_{i t}+\rho Z_{i}+\alpha_{i}+\varepsilon_{i t}
$$

where $P_{i t}$ and $C_{i t}$ are the crude oil price in regions $i$ and periods $t$ and carbon intensity level in regions $i$ and periods $t$ and where $\alpha_{i}$ are the (unobserved) individual region effects, $\rho Z_{i}$ are time-invariant explanatory variables, and $\varepsilon_{i t}$ is the error term with

$$
E\left(\varepsilon_{i t}\right)=0
$$

It is assumed that

$$
\begin{gathered}
E\left(\alpha_{i}\right)=0, \\
E\left(\alpha_{i} C_{i t}\right)=0 .
\end{gathered}
$$

Introducing the GMM's first difference approach, the model takes care of the individual effects $\alpha_{i}$ and time-invariant explanatory variables $Z_{i}$

$$
\begin{aligned}
\left(P_{t}-P_{t-1}\right)= & \gamma\left(P_{t-1}-P_{t-2}\right)+\beta\left(C_{i t}-C_{i, t-1}\right) \\
& +\varepsilon_{i t}-\varepsilon_{i t-1}
\end{aligned}
$$

for $t=-2, \ldots, T$.

To overcome the problems of endogeneity in the model, Arellano and Bond [21] recommend using instrumental variables. More specifically, they propose using lagged values of the explanatory variables as instruments (ibid). It is also assumed that all time varying explanatory variables, in this case, carbon intensity levels, are strictly exogenous; that is,

$$
E\left(C_{i t}^{\prime} \varepsilon_{i t}\right)=0 .
$$

Let $\Delta=(1-L)$, where $L$ denotes the lag operator and

$$
Y_{i t}=\left(p_{i t 0}, p_{i t 1}, \ldots, y_{i, t-2}, c_{i}^{\prime}\right)^{\prime}\left(t-1+T K_{1}, 1\right),
$$

where $c_{i}^{\prime}=\left(c_{i 1}^{\prime}, \ldots, c_{i T}\right)$

And for each period, there is the existence of the following orthogonal conditions:

$$
E\left(p_{i t} \Delta \varepsilon_{i t}\right)=0
$$

where $t=-2, \ldots, T$.

Introducing the stacked $(T-1)$ first difference equations in matrix form gives the following:

$$
\Delta P_{i t}=\Delta P_{i t-1} \gamma+\Delta C_{i t} \beta+\Delta \varepsilon_{i t},
$$

where $i=1, \ldots, N$.

This study estimates the $K_{i}+1$ parameters of the $\theta=$ $\left(\gamma, \beta^{\prime}\right)^{\prime}$ vector, where there are $T(T-10)\left(K_{1}+1 / 2\right)$ moment conditions (if $C_{i t}$ are strictly exogenous) that can be presented as

$$
E\left(W_{i}, \Delta \varepsilon_{i t}\right)=E\left[W_{i}\left(\Delta P_{i t}-\Delta P_{i t-1} \gamma-\Delta C_{i t} \beta\right)\right]=0 .
$$

However, the above model specifications can also be adjusted further, with reference to the available data in some regions. This study estimates the relationship between crude oil prices and carbon intensity using the dynamic panel model in (8) above.

3.1. Diagnostic Tests. The validity of the instruments specified in the estimation process using the $\mathrm{AB}$ GMM approach is tested using the Sargan test of overidentifying restrictions. The Sargan test is used to check whether the instruments are truly exogenous which is based on the assumption that the residuals are uncorrelated with the set of exogenous variables. It is asymptotically distributed as chi-square $\left(\chi^{2}\right)$ and tests 
TABLE 1: Model estimates.

\begin{tabular}{lcc}
\hline & Panel 1: baseline & $\begin{array}{c}\text { Panel 2: structural } \\
\text { breaks control }\end{array}$ \\
\hline Oil price (lag) & & \\
Estimate & 0.85 & 0.81 \\
$\quad$ Standard error & $(0.079)$ & $(0.0430)$ \\
$\quad P$ value & 0.000 & 0.000 \\
Carbon intensity & & \\
$\quad$ Short run & 2.1 & 1.6 \\
$\quad$ Standard error & $(0.8772)$ & $(0.7436)$ \\
$\quad P$ value & 0.015 & 0.024 \\
Long run & 14 & 8.4 \\
\hline
\end{tabular}

the null hypothesis that the instruments are valid. The null hypothesis can only be rejected if the $P$ value of the chisquare is less than 0.1 or 0.05 . Therefore, a model with valid or exogenous instruments would have a higher $P$ value of the Sargan statistic. Sargan test is preferred to other weak instruments tests such as Hansen test and $F$-test because it is the standard test for weak instruments under the $A B$ dynamic panel model, less vulnerable to instrument proliferation and based on the optimal weighting matrix [46]. It is pertinent to use Sargan test to confirm the validity of the instruments and indicate that the error term is uncorrelated with the instruments when the dynamic panel model is used [47].

Similarly, it is also vital to check for the nonexistence of serial correlation in the error term, as consistency of the estimates depends on it. This study carries out the first order (AR1) and second order (AR2) serial correlation tests to determine whether serial correlation exists or not. Based on a priori theoretical assumptions, the rejection of the null hypothesis for first order serial correlation (AR1) is expected by design or default but failure to reject the null hypothesis of the absence of second order serial correlation (AR2) leads to the conclusion that the original error terms are serially uncorrelated, while the test statistics are asymptotically distributed as standard normal variables. The dynamic panel model is correctly specified if the researcher fails to reject the null hypothesis based on the outcome of the second order (AR2) serial correlation test. This means that the estimated coefficients in the model are consistent and reliable.

The study also identified some outliers in the oil prices data which are tested for structural breaks. The structural breaks are controlled, by introducing dummy variables accordingly. The dummy variables are Y1986, Y1990, Y1998, Y2000, and Y2008.

\section{Empirical Results}

The AB dynamic panel model results as shown in Table 1 contain the estimates of the coefficients of the effects of carbon intensity on crude oil prices for the baseline or reference case (column 2), where the direct relationship between crude oil prices and carbon intensity is estimated, and the control(s) for the outliers/structural breaks identified in the crude oil price data are reported in column 3. The dummy variables serve as impulse and control variables to determine the effects of predetermined shocks as a result of rise and fall in oil prices. The deterministic variables are used to control for the outliers observed in the crude oil price data for 1986, 1990, 1998, 2000, and 2008. These variables capture the effects of identified events related to the oil price data and improve the robustness of the model.

Some of the outliers could be explained as a result of the gulf oil crisis in 1990, the new millennium related price shocks in 1999, and the price rise in 2008, respectively. The study focuses on the short run and long run carbon intensity effects on crude oil prices. The estimated panel results are presented in Table 1.

Model/panel 1 shows the panel result for the reference case. The result indicates that a $1 \%$ change in carbon intensity causes about $2.1 \%$ change in crude oil prices in the short run and $14 \%$ change in the long run. It shows a positive relationship between crude oil prices and carbon intensity and it is statistically significant at all levels. Column 3 shows the panel results when the control variables for the outliers are introduced. It indicates a statistically significant, positive relationship between oil prices and carbon intensity. The relationship as estimated shows that $1 \%$ change in carbon intensity causes $1.6 \%$ change in oil prices in the short run and about $8.4 \%$ in the long run. The speed of adjustment of crude oil prices to changes in carbon intensity in a period is about $15 \%$ in the reference case and $19 \%$ in the controlled model (the computed regional results are not reported here but can be requested from the author). Although the methodology of this study is different from the existing studies in the literature, the estimates are similar. Awerbuch and Sauter [37] found that the effect of carbon emissions reduction on oil prices is within the range of $3 \%-10 \%$, while this study finds that the effect of carbon intensity on oil price is within the range of $1.6 \%-2.1 \%$ in the short run and $8.4 \%-14 \%$ in the long run. This study's results find a positive relationship between oil price and carbon intensity, which is also in line with McKibbin and Wilcoxen [40], Ghanem et al. [35], Bernstein et al. [41], Bartsch and Muller [42], Pershing [36], and Polidano et al. [43], all of which found that there is a relationship between oil prices and greenhouse gases emissions reduction activity.

4.1. Sargan and Serial Correlation Tests. The Sargan and second order serial correlation (AR2) diagnostic tests shown in Table 2 indicate that the instruments are valid and there is no serial correlation. With the outcome of the Sargan test, the study failed to reject the null hypothesis of the Sargan test that the instruments are valid. For the serial correlation, the study also failed to reject the second order serial correlation null hypothesis that there is no autocorrelation. The outcome of the diagnostic tests shows that the results are robust, reliable, efficient, and consistent for the models/panels reported in Table 1.

\section{Conclusion}

From the study's results presented in Table 1, it is safe to state that carbon intensity affects crude oil prices, especially in the 
TABle 2: Diagnostic tests.

\begin{tabular}{lcc}
\hline Diagnostics tests & Panel 1: baseline & $\begin{array}{c}\text { Panel 2: structural } \\
\text { breaks control }\end{array}$ \\
\hline Sargan test: & & \\
$\quad$ chi2 (156) & 163.28 & 185.46 \\
Prob > chi2 & 0.3286 & 0.335 \\
Serial correlation test: & & \\
AR(1): $z$ & -6.93 & -3.02 \\
$\operatorname{Pr}>z$ & $(0.000)$ & $(0.000)$ \\
$\operatorname{AR}(2): z$ & -1.49 & -5.08 \\
$\operatorname{Pr}>z$ & $(0.137)$ & $(0.160)$ \\
\hline
\end{tabular}

TABLE 3: Countries considered in the European region.

\begin{tabular}{lc}
\hline 1 & Austria \\
2 & Belgium \\
3 & Cyprus \\
4 & Denmark \\
5 & Finland \\
6 & France \\
7 & Germany \\
8 & Greece \\
9 & Ireland \\
10 & Italy \\
11 & Luxembourg \\
12 & Malta \\
13 & Netherlands \\
14 & Norway \\
15 & Portugal \\
16 & Romania \\
17 & Spain \\
18 & Sweden \\
19 & Switzerland \\
20 & Turkey \\
21 & United Kingdom \\
\hline &
\end{tabular}

long run. This shows that a unit change in the level of carbon intensity has a significant effect on oil prices. However, the rate of effect or impact of this influence from the estimated "speed of adjustment" is low at 15\% and 19\%.

With reference to climate change mitigation activity, these empirical outcomes show that there is a relationship between crude oil prices and $\mathrm{CO}_{2}$ emissions reduction.

Although so many factors affect crude oil prices, this study has shown that there is a statistically significant relationship between crude oil prices and climate change mitigation activity using the AB dynamic panel model. Other factors that affect the prices of crude oil such as production, supply, demand, and taxes may have more or larger effects but it is evident in this study that climate change mitigation activity also affects oil prices.

This study concludes from the empirical outcomes that significant changes in crude oil prices can be induced by changes in climate change mitigation activity in a country or
TABle 4: Countries considered in the Central and South American region.

\begin{tabular}{|c|c|}
\hline 1 & Antigua and Barbuda \\
\hline 2 & Argentina \\
\hline 3 & The Bahamas \\
\hline 4 & Barbados \\
\hline 5 & Belize \\
\hline 6 & Bolivia \\
\hline 7 & Brazil \\
\hline 8 & Cayman Islands \\
\hline 9 & Chile \\
\hline 10 & Colombia \\
\hline 11 & Costa Rica \\
\hline 12 & Cuba \\
\hline 13 & Dominica \\
\hline 14 & Dominican Republic \\
\hline 15 & Ecuador \\
\hline 16 & El Salvador \\
\hline 17 & French Guiana \\
\hline 18 & Grenada \\
\hline 19 & Guatemala \\
\hline 20 & Guyana \\
\hline 21 & Haiti \\
\hline 22 & Honduras \\
\hline 23 & Jamaica \\
\hline 24 & Martinique \\
\hline 25 & Netherlands Antilles \\
\hline 26 & Nicaragua \\
\hline 27 & Panama \\
\hline 28 & Peru \\
\hline 29 & Puerto Rico \\
\hline 30 & Saint Kitts and Nevis \\
\hline 31 & Saint Lucia \\
\hline 32 & Saint Vincent/Grenadines \\
\hline 33 & Trinidad and Tobago \\
\hline 34 & Uruguay \\
\hline 35 & Venezuela \\
\hline 36 & U.S. Virgin Islands \\
\hline
\end{tabular}

region that is a net importer of crude oil, which are majorly the industrialised countries and Annex 1 countries under the Kyoto Protocol. The study outcomes show that it is safe to state that climate change mitigation activities especially $\mathrm{CO}_{2}$ reductions using carbon intensity as indicator are expected to have effects on crude oil prices.

There are also some research implications from this study. The carbon intensity data used in this study covers the entire economy but further research can look into estimating a model of carbon intensity levels in transportation sector only using the utilisation of renewable energy sources like biofuel consumption. The reason for such model is to investigate the difference between carbon intensity levels in the economy as whole and the carbon intensity levels in the transportation 
TABLE 5: Countries considered in the Middle East region.

\begin{tabular}{lc}
\hline 1 & Bahrain \\
2 & Iran \\
3 & Iraq \\
4 & Israel \\
5 & Jordan \\
6 & Kuwait \\
7 & Lebanon \\
8 & Oman \\
9 & Qatar \\
10 & Saudi Arabia \\
11 & Syria \\
12 & United Arab Emirates \\
13 & Yemen \\
\hline
\end{tabular}

sector which accounts for about $80 \%$ of crude oil consumptions. However, the insufficient data on biofuel consumption in all the regions made the estimation of this model difficult at this stage. Therefore, as data on biofuel consumption in these regions becomes available in the future, it may be necessary to also estimate the impacts of biofuel consumption induced carbon intensity levels or transportation sector based carbon intensity level (using sectoral trends such as "electric cars") on crude oil prices.

It can also be assumed that an increase in crude oil prices may have a reasonably significant effect on climate change mitigation policy measures through investments in climate change mitigation technologies. Investments in the technology required for climate change mitigation have become a burden on governments across the world. Private investors are yet to fully embrace green investments as expected due to the risk of negative returns on investment. In some countries or regions where there are growing interests in green investments, it is because either the government subsidises these private firms or they are enjoying some levels of tax waivers. Therefore, there is need for further investigation on the transmission of the impact of crude oil prices on climate change mitigation investments.

\section{Appendix}

\section{Regions}

In the North American region, the United States of America (USA), Canada, Mexico, and Bermuda are the countries considered (see Tables 3, 4, 5, 6, and 7).

\section{Conflict of Interests}

The author declares that there is no conflict of interests regarding the publication of this paper.

\section{Acknowledgments}

The author is indebted to the Petroleum Technology Development Fund (PTDF) and Economics Division, University of
TABLE 6: Countries considered in the African region.

\begin{tabular}{|c|c|}
\hline 1 & Algeria \\
\hline 2 & Angola \\
\hline 3 & Benin \\
\hline 4 & Botswana \\
\hline 5 & Burkina Faso \\
\hline 6 & Burundi \\
\hline 7 & Cameroon \\
\hline 8 & Cape Verde \\
\hline 9 & Central African Republic \\
\hline 10 & Chad \\
\hline 11 & Comoros \\
\hline 12 & Congo (Brazzaville) \\
\hline 13 & Congo (Kinshasa) \\
\hline 14 & Cote d'Ivoire (Ivory Coast) \\
\hline 15 & Djibouti \\
\hline 16 & Egypt \\
\hline 17 & Equatorial Guinea \\
\hline 18 & Ethiopia \\
\hline 19 & Gabon \\
\hline 20 & The Gambia \\
\hline 21 & Ghana \\
\hline 22 & Guinea \\
\hline 23 & Guinea-Bissau \\
\hline 24 & Kenya \\
\hline 25 & Lesotho \\
\hline 26 & Liberia \\
\hline 27 & Libya \\
\hline 28 & Madagascar \\
\hline 29 & Malawi \\
\hline 30 & Mali \\
\hline 31 & Mauritania \\
\hline 32 & Mauritius \\
\hline 33 & Morocco \\
\hline 34 & Mozambique \\
\hline 35 & Niger \\
\hline 36 & Nigeria \\
\hline 37 & Reunion \\
\hline 38 & Rwanda \\
\hline 39 & Sao Tome and Principe \\
\hline 40 & Senegal \\
\hline 41 & Seychelles \\
\hline 42 & Sierra Leone \\
\hline 43 & Somalia \\
\hline 44 & South Africa \\
\hline 45 & Sudan and South Sudan \\
\hline 46 & Swaziland \\
\hline 47 & Tanzania \\
\hline 48 & Togo \\
\hline 49 & Tunisia \\
\hline 50 & Uganda \\
\hline 51 & Zambia \\
\hline 52 & Zimbabwe \\
\hline
\end{tabular}

Stirling, for the grant to carry out this study, Dr. Ian Lange for his immense contributions, and the participants of the numerous workshops, seminars, and conferences where the 
TABLE 7: Countries considered in Asia and Oceania region.

\begin{tabular}{lc}
\hline 1 & Afghanistan \\
2 & American Samoa \\
3 & Australia \\
4 & Bangladesh \\
5 & Bhutan \\
6 & Brunei \\
7 & Burma (Myanmar) \\
8 & Cambodia \\
9 & China \\
10 & Fiji \\
11 & Guam \\
12 & Hong Kong \\
13 & India \\
14 & Indonesia \\
15 & Japan \\
16 & Kiribati \\
17 & North Korea \\
18 & South Korea \\
19 & Laos \\
20 & Malaysia \\
21 & Maldives \\
22 & Mongolia \\
23 & Nepal \\
24 & New Zealand \\
25 & Pakistan \\
26 & Papua New Guinea \\
27 & Philippines \\
28 & Samoa \\
29 & Singapore \\
30 & Sri Lanka \\
31 & Taiwan \\
32 & Thailand \\
33 & Tonga \\
34 & Vanuatu \\
35 & Vietnam \\
36 &
\end{tabular}

author's preliminary findings were presented, especially at the University of Stirling Economics Division's Workshop, for their positive feedback.

\section{References}

[1] R. Bacon, "Modelling the price of oil," Oxford Review of Economic Policy, vol. 7, no. 2, pp. 17-34, 1991.

[2] S. Dées, P. Karadeloglou, R. K. Kaufmann, and M. Sánchez, "Modelling the world oil market: assessment of a quarterly econometric model," Energy Policy, vol. 35, no. 1, pp. 178-191, 2007.

[3] J. V. Mitchell, A New Era for Oil Prices, Chatham House Report, 2006.

[4] M. S. Haigh, J. Hranaiova, and J. Overdahl, "Price volatility, liquidity provision and the role of managed money traders in energy futures markets," US Commodity Futures Trading Commission Working Paper, 2005.
[5] L. Kogan, S. A. Ross, J. Wang, and M. M. Westerfield, “The price impact and survival of irrational traders," MIT Sloan Working Paper No. 4293-03, 2003.

[6] OPEC, "Who gets what from imported oil?" OPEC report, 2012, http://www.opec.org/opec_web/en/publications/341.htm.

[7] P. Stevens and M. Hulbert, Oil Prices: Energy Investment, Political Stability in the Exporting Countries and OPEC's Dilemma, EEDP Programme Paper: 2012/03, Chatham House, London, UK, 2012.

[8] B. Fattouh, Structural Model, the Demand-Supply Framework and Informal Approaches, CFMS, SOAS, 2007.

[9] K. King, A. Deng, and D. Metz, "An econometric analysis of oil price movements: the role of political events and economic news, financial trading and market fundamentals," Bates White Economic Report 2012/01, 2012.

[10] OPEC, “OPEC long term strategy," OPEC Report 2010/10, 2010.

[11] IPIECA, "The oil and gas industry and climate change," International Petroleum Industry Environmental Conservation Association's Report, IPIECA, London, UK, 2007.

[12] Y. Kaya, "Impact of carbon dioxide emission control on GNP growth: interpretation of proposed scenarios," in Proceedings of the IPCC Energy and Industry Subgroup, Response Strategies Working Group, Paris, France, 1990.

[13] H. H. Rogner, D. Zhou, R. Bradley et al., "Introduction," in Climate Change 2007: Mitigation, B. Metz, O. R. Davidson, P. R. Bosch, R. Dave, and L. A. Meyer, Eds., Contribution of Working Group III to the Fourth Assessment Report of the Intergovernmental Panel on Climate Change, Cambridge University Press, Cambridge, UK, 2007.

[14] United Nation Division for Sustainable Development (UN), "Measuring progress towards sustainable development and climate change-the potential of the CSD indicators of sustainable development," in Proceedings of the Expert Group Meeting on Climate Change and Sustainable Development-The Role of Indicators, United Nation Division for Sustainable Development, New York, NY, USA, October 2008.

[15] J. W. Sun, "Changes in energy consumption and energy intensity: a complete decomposition model," Energy Economics, vol. 20, no. 1, pp. 85-100, 1998.

[16] J. W. Sun and B. W. Ang, "Some properties of an exact energy decomposition model," Energy Economics, vol. 25, no. 12, pp. $1177-1188,2000$.

[17] N. Helme and C. Leining, "Designing future international actions on climate change," in Proceedings of the UNFCCC 18th Session of the Subsidiary Bodies, Bonn, Germany, 2003.

[18] World Resource Institute (WRI), Climate Analysis Indicators Tool (CAIT), 2013, https://sites.google.com/site/climateanalysisindicatorstool/cait-international-8-0.

[19] Intergovernmental Panel on Climate Change (IPCC), Contribution of Working Group III to the Fourth Assessment Report, Cambridge University Press, Cambridge, UK, 2007.

[20] J. Barnett, S. Dessai, and M. Webber, "Will OPEC lose from the kyoto protocol?" Energy Policy, vol. 32, no. 18, pp. 2077-2088, 2004.

[21] M. Arellano and S. Bond, "Some tests of specification for panel data: Monte Carlo evidence and an application to employment equations," Review of Economic Studies, vol. 58, no. 2, pp. 277297, 1991.

[22] E. Mileva and N. Siegfried, Oil Market Structure, Network Effects and the Choice of Currency for Oil Invoicing, ECB occasional paper series no. 77, 2007. 
[23] M. A. Adelman, "Modelling world oil supply," The Energy Journal, vol. 14, no. 1, pp. 1-32, 1993.

[24] J. M. Griffin, "OPEC behaviour: a test of alternative hypotheses," American Economic Review, vol. 75, pp. 954-963, 1985.

[25] A. F. Alhajji and D. Huettner, "OPEC and world crude oil markets from 1973 to 1994: cartel, oligopoly, or competitive?” The Energy Journal, vol. 21, no. 3, pp. 31-60, 2000.

[26] S. Dees, P. Karadeloglou, R. Kaufmann, and M. Sánchez, "Does OPEC matter? An econometric analysis of oil prices," The Energy Journal, vol. 25, no. 4, pp. 67-90, 2004.

[27] Energy Intelligence, Understanding the Oil and Gas Industries, Energy Intelligence, New York, NY, USA, 2004.

[28] D. Barboza and A. R. Sorkin, "Chinese oil giant in takeover bid for US corporation," The New York Times, 2005.

[29] K. Grant, D. Ownby, and S. R. Peterson, Understanding today's crude oil and product markets. A Policy Analysis Study by Lexecon undertaken for API, 2006.

[30] J. D. Hamilton, "Understanding crude oil prices," The Energy Journal, vol. 30, no. 2, pp. 179-206, 2009.

[31] UNFCCC (United Nation Framework Convention on Climate change), "Fact Sheet: The need for Mitigation," UNFCCC Report, 2009.

[32] Energy Information Administration (EIA), Energy intensity Data, Energy Information Administration (EIA), Washington, DC, USA, 2012, http://www.eia.gov/cfapps/ipdbproject/IEDIndex3.cfm?tid=91\&pid=46\&aid $=31$.

[33] Energy Modelling Forum (EMF), "Energy efficiency and climate change," EMF report 25, 1, 2011.

[34] OECD, "Climate change mitigation: what do we do?" OECD Report, 2008.

[35] S. Ghanem, R. Lounnas, and G. Brennand, "The impact of emissions trading on OPEC," OPEC Review June, vol. 23, no. 2, pp. 79-112, 1999.

[36] J. Pershing, "Fossil fuel implications of climate change mitigation responses," in Sectoral and Economic Costs and Benefits of GHG Mitigation, L. Bernstein and J. Pan, Eds., Intergovernmental Panel on Climate Change, Bilthoven, The Netherlands, 2000.

[37] S. Awerbuch and R. Sauter, "Exploiting the oil-GDP effect to support renewables deployment," Energy Policy, vol. 34, no. 17, pp. 2805-2819, 2006.

[38] P. Henman, "Computer modeling and the politics of greenhouse gas policy in Australia," Social Science Computer Review, vol. 20, no. 2, pp. 161-173, 2002.

[39] N. Lacasta, S. Dessai, and E. Powroslo, "Consensus among many voices: articulating the European Unions position on climate change," Golden Gate University Law Review, vol. 32, pp. 351414, 2002.

[40] W. J. McKibbin and P. J. Wilcoxen, "Estimates of the costs of Kyoto: Marrakesh versus the McKibbin-Wilcoxen blueprint," Energy Policy, vol. 32, no. 4, pp. 467-479, 2004.

[41] P. M. Bernstein, W. D. Montgomery, and T. F. Rutherford, "Global impacts of the Kyoto agreement: results from the MS-MRT model," Resource and Energy Economics, vol. 21, no. 4, pp. 375413, 1999.

[42] U. Bartsch and B. Muller, "Impacts of the Kyoto Protocol on fossil fuels," in Sectoral and Economic Costs and Benefits of GHG Mitigation, L. Bernstein and J. Pan, Eds., Intergovernmental Panel on Climate Change, Bilthoven, The Netherlands, 2000.

[43] C. Polidano, F. Jotzo, E. Heyhoe, G. Jakeman, K. Woffenden, and B. Fisher, "The Kyoto Protocol and developing countries: impacts and implications for mechanism design," ABARE Research Report, Australian Bureau of Agricultural and Research Economics, Canberra, Australia, 2000.

[44] A. Grübler, N. Nakićenović, and D. G. Victor, "Dynamics of energy technologies and global change," Energy Policy, vol. 27, no. 5, pp. 247-280, 1999.

[45] J. Weyant, An Introduction to the Economics of Climate Change Policy, Pew Centre on Global Climate Change, Arlington, Va, USA, 2000.

[46] R. MacDonald, A. Damasceno, and F. Vieira, "The role of institutions in cross-section income and panel data growth models: a deeper investigation on the weakness and proliferation of instruments," Working Papers, Department of Economics, University of Glasgow, 2010.

[47] C. G. Bowsher, "On testing overidentifying restrictions in dynamic panel data models," Economics Letters, vol. 77, no. 2, pp. 211-220, 2002. 


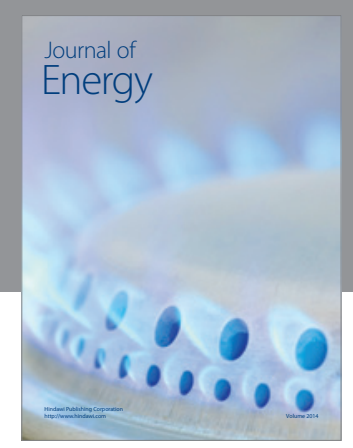

Journal of

Industrial Engineering
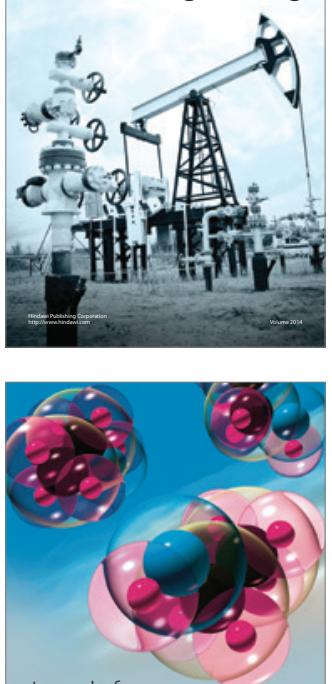

Fuels
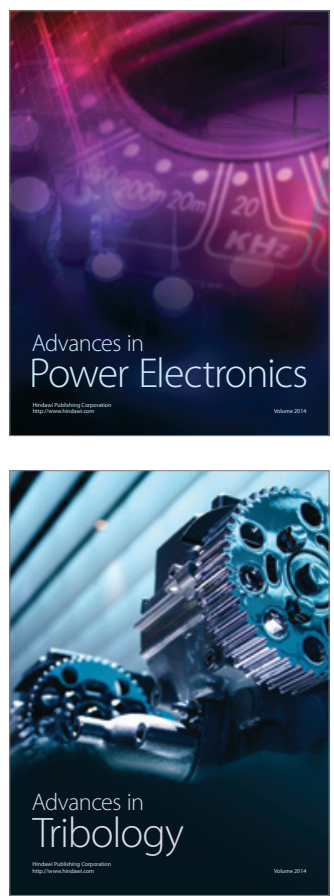

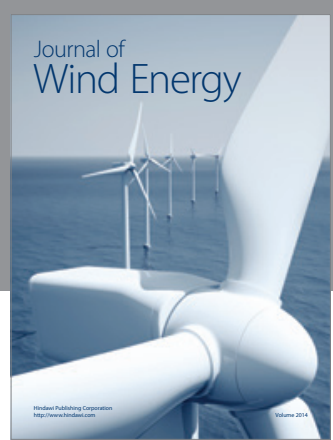

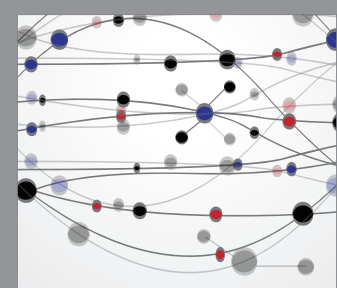

The Scientific World Journal

Submit your manuscripts at http://www.hindawi.com

Journal of

Structures
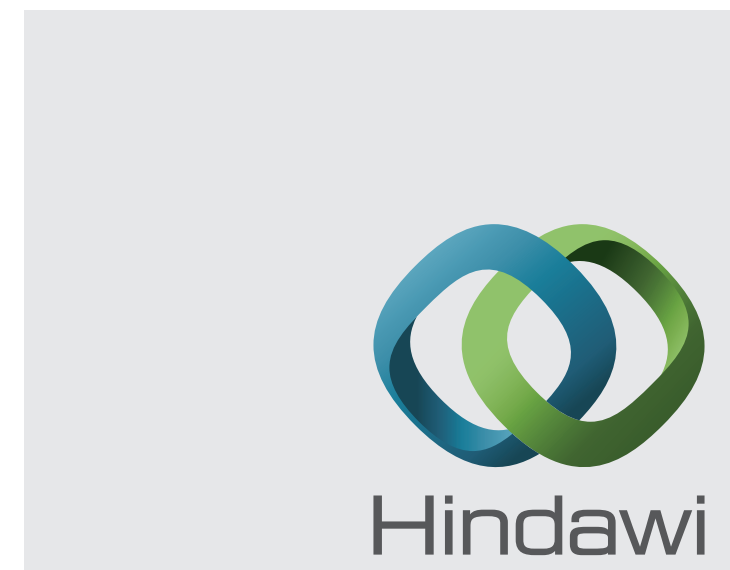

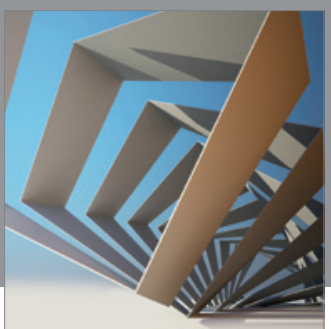

Rotating

Machinery
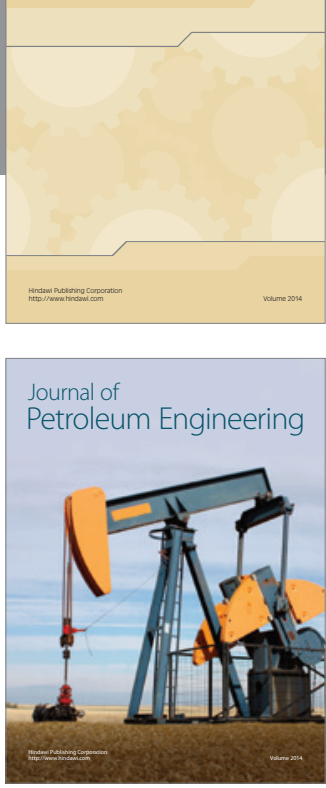

Journal of

Solar Energy
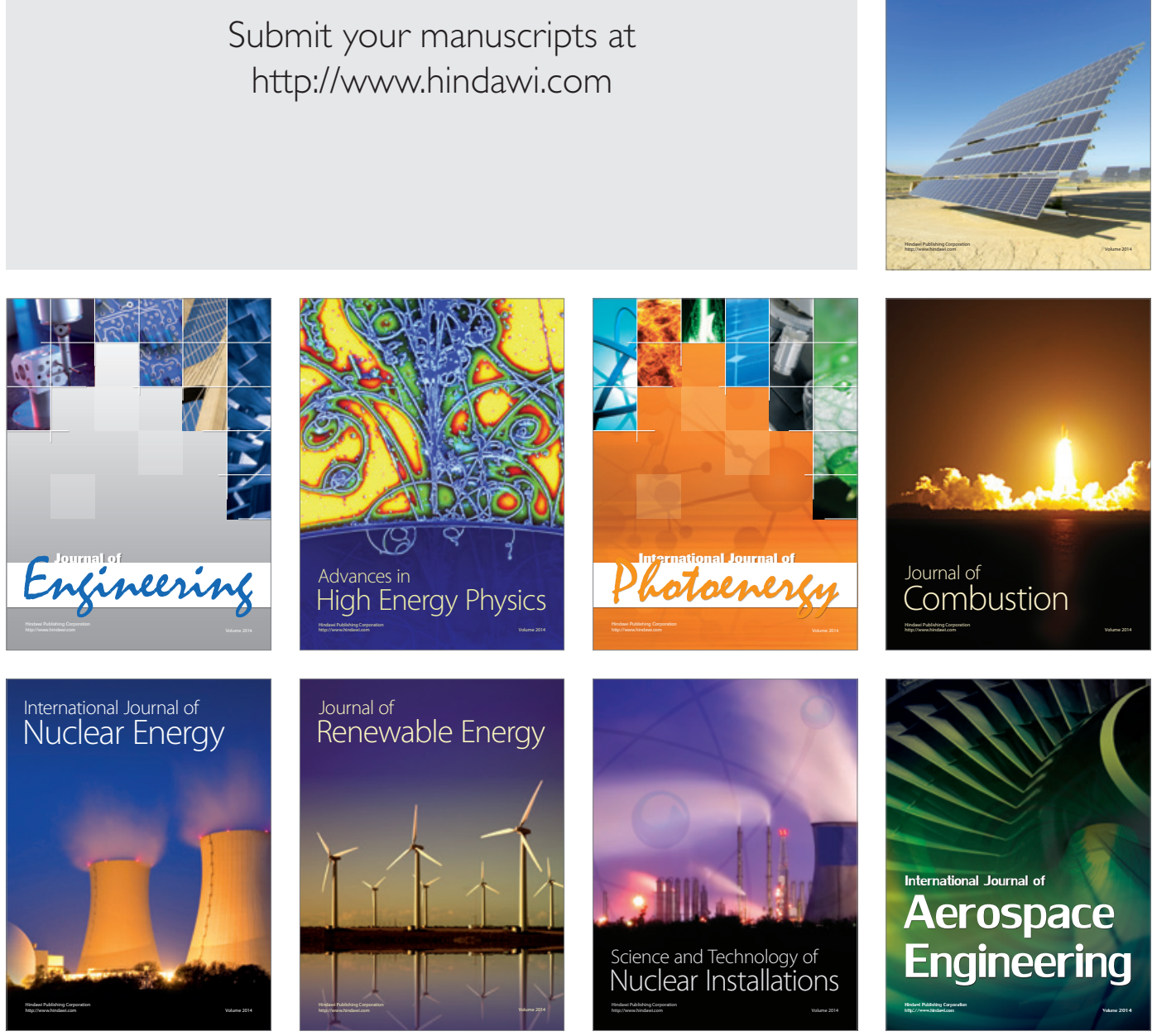